\title{
CSF imaging in benign intracranial hypertension
}

\author{
A. EVERETte JAMES ${ }^{1}$, J. C. HARBERT ${ }^{2}$, P. B. HOFFER ${ }^{3}$, AND F. H. DeLAND \\ From the Department of Radiology and Radiological Sciences, \\ Johns Hopkins Medical Institutions, Baltimore, Maryland 21205, U.S.A.
}

SYNOPSIS The cisternographic images in 10 patients with benign intracranial hypertension were reviewed. Nine were normal. Transfer of labelled tracer from the subarachnoid space was measured in five patients and was found to be abnormal in only two. The relation of these findings to the proposed pathophysiological alterations is discussed.

Benign intracranial hypertension (pseudotumor cerebri) is a transient entity of unknown aetiology usually manifest by clinical symptoms of headache, visual blurring, ophthalmological dis-

\footnotetext{
1 Address for reprints: Dr A. E. James, Director, Radiological Research, Johns Hopkins Medical Institutions, Baltimore, Md., U.S.A. 2 Georgetown Medical School, Washington, D.C., U.S.A.

3 University of Chicago School of Medicine, Chicago, III., U.S.A.

4 University of Florida Medical School, Gainesville, Florida, U.S.A.
}

orders of choked discs, retinal haemorrhages, and sixth nerve palsies. Except for raised pressure, other parameters of the cerebrospinal fluid (CSF) are normal (Hagberg and Sillanpää, 1964). This association of abnormalities is of limited duration (average in 100 patients, 10 weeks) (Guidetti et al., 1968) and may be managed by 'conservative means' (diet, fluid restriction, serial drainage of CSF by lumbar punctures) or by surgical subtemporal decom-

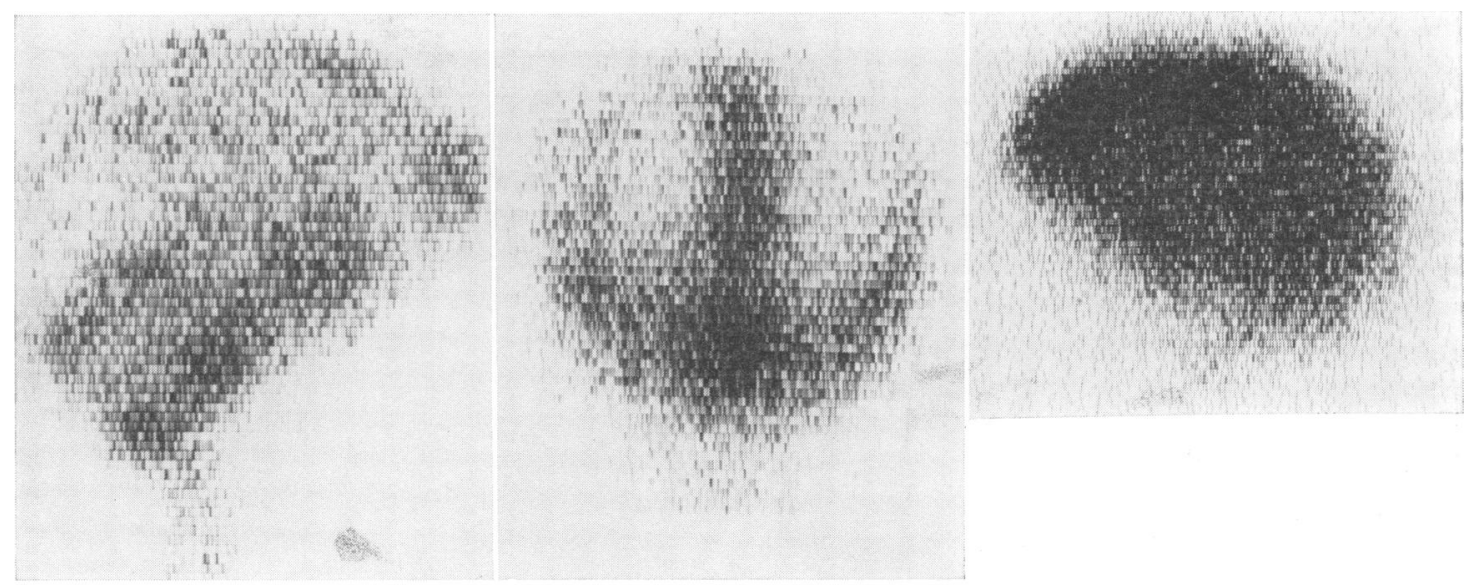

(a)

(b)

(c)

FIG. 1. (a) Right lateral view of cisternogram six hours after lumbar subarachnoid injection ( $1 \mathrm{mCi}{ }^{169} \mathrm{Yb}$ $D T P A)$. Normal distribution over cerebral cortex is present. (b) Anterior view at six hours. The radiopharmaceutical is present in the basal cisterns, laterally over the cerebral convexities, and between the cerebral hemispheres. No ventricular radioactivity is seen. (c) Left lateral view at 24 hours. Generalized distribution of radiopharmaceutical over the cerebral convexities is present with concentration in the parasagittal area superiorly and anteriorly. 
TABLE

CLINICAL DETAILS OF 10 PATIENTS

\begin{tabular}{|c|c|c|c|c|c|c|c|c|c|c|c|c|}
\hline \multirow[t]{2}{*}{ Name } & \multirow{2}{*}{$\begin{array}{l}\text { Age } \\
(y r)\end{array}$} & \multirow[t]{2}{*}{ Sex } & \multirow{2}{*}{$\begin{array}{l}\text { Dura- } \\
\text { tion* } \\
\text { (mth) }\end{array}$} & \multirow{2}{*}{$\begin{array}{c}L P(O P) \\
\left(m m H_{2} O\right)\end{array}$} & \multirow{2}{*}{$\begin{array}{l}\text { Radiopharma- } \\
\text { ceuticul }\end{array}$} & \multicolumn{4}{|c|}{ CSF image } & \multirow{2}{*}{$\begin{array}{c}\text { Abnormal } \\
\text { parasagittal } \\
\text { concentration }\end{array}$} & \multirow{2}{*}{$\begin{array}{c}\text { Ventricular } \\
\text { entry }\end{array}$} & \multirow{2}{*}{ Therapy } \\
\hline & & & & & & $2 h r$ & $6 h r$ & $24 h r$ & $48 h r$ & & & \\
\hline F.F. & 60 & $\mathbf{F}$ & 12 & $500-600$ & $\begin{array}{c}100 \mu{ }^{131 I} \\
\text { HSA }\end{array}$ & Basal & Convex & Clearing & - & - & 一 & Cons. \\
\hline G.M. & 19 & $\mathbf{F}$ & 48 & $500-600$ & $\begin{array}{c}1 \mathrm{mCi}{ }^{169} \mathrm{Yb} \\
\text { DTPA }\end{array}$ & Basal \pm & - & Convex & Para & + & - & Cons. \\
\hline D.C. & 30 & $\mathbf{F}$ & 36 & 400 & $\begin{array}{c}1 \mathrm{mCi}{ }^{169} \mathrm{Yb} \\
\text { DTPA }\end{array}$ & Basal & Sylvian & Sylvian & - & - & - & - \\
\hline G.R. & 33 & $\mathbf{F}$ & 4 & 280 & $\begin{array}{r}100 \mu \mathrm{Ci} \\
131 J \mathrm{HSA}\end{array}$ & Basal & Sylvian & Convex & - & - & - & Cons. \\
\hline J.C. & 39 & $\mathbf{F}$ & $1 \frac{1}{2}$ & 210 & $\begin{array}{r}100 \mu \mathrm{Ci} \\
131 \text { I HSA }\end{array}$ & Basal & Sylvian & Convex & - & - & - & - \\
\hline J.W. & 31 & $\mathbf{F}$ & 7 & 200 & $\begin{array}{r}100 \mu \mathrm{Ci} \\
131 \mathrm{I} \mathrm{HSA}\end{array}$ & Basal & Sylvian & Convex & - & - & - & $\begin{array}{l}\text { Surg. } \\
\text { decomp }\end{array}$ \\
\hline C.W. & 20 & $\mathbf{F}$ & 48 & 500 & $\begin{array}{r}100 \mu \mathrm{Ci} \\
131 \text { I HSA }\end{array}$ & Basal & Convex & Para & - & - & - & - \\
\hline A.S. & 22 & $\mathbf{F}$ & 84 & 650 & $\begin{array}{c}100 \mu \mathrm{Ci} \\
131 \mathrm{I} \mathrm{HSA}\end{array}$ & Basal & Convex & Para & - & - & - & - \\
\hline G.L. & 44 & $\mathbf{M}$ & 6 & 350 & $\begin{array}{c}450 \mu \mathrm{Ci} \\
111 \text { In DTPA }\end{array}$ & Basal & Convex & Para & Para & - & - & $\begin{array}{l}\text { Surg. } \\
\text { decomp }\end{array}$ \\
\hline S.E. & 6 & $\mathbf{M}$ & 12 & 250 & $\underset{2 \mathrm{mCI}}{{ }^{\mathrm{g} \mathrm{m}} \mathrm{Tc} \mathrm{HSA}}$ & Basal & Convex & Convex & - & - & - & $\begin{array}{l}\text { Surg. } \\
\text { decomp }\end{array}$ \\
\hline
\end{tabular}

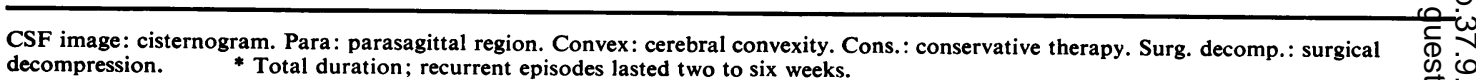

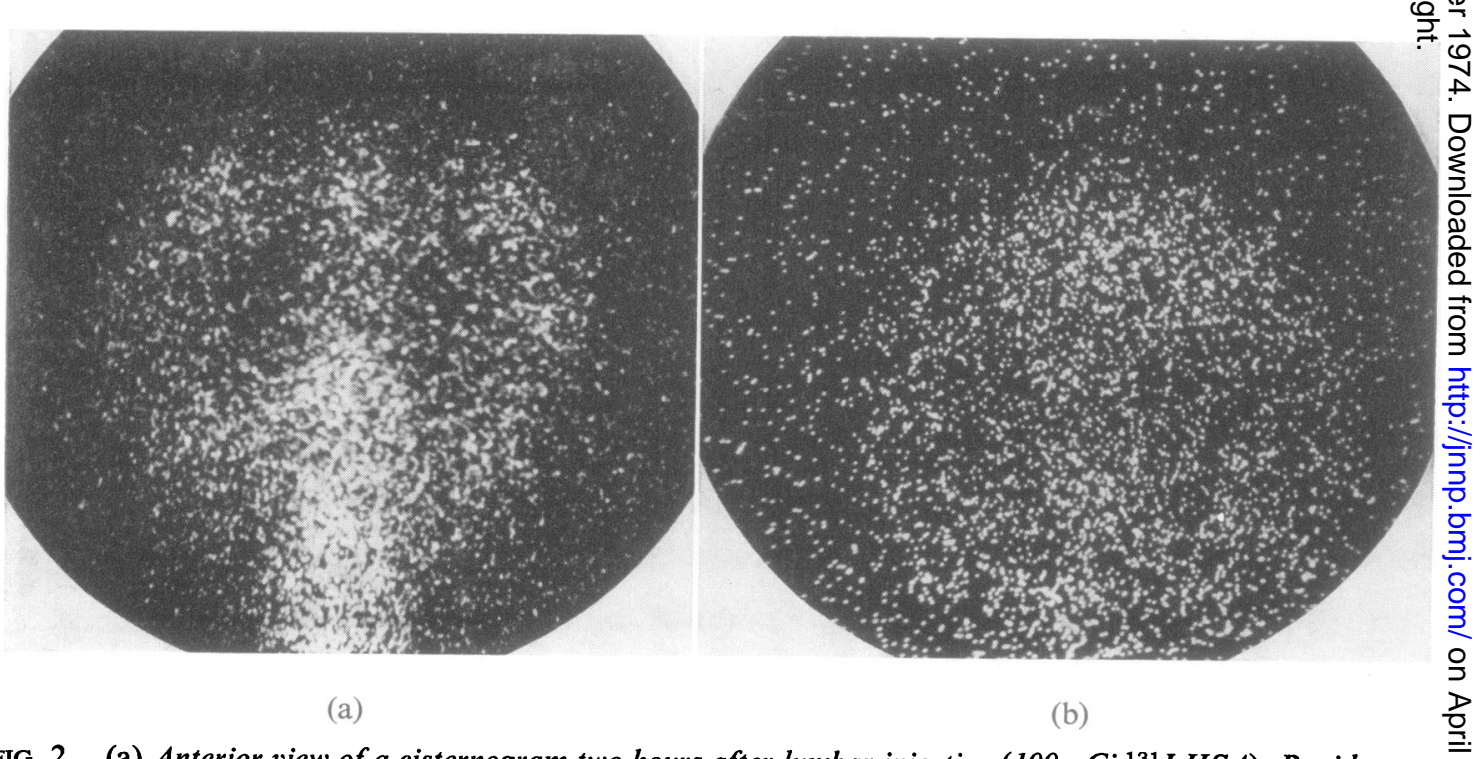

FIG. 2. (a) Anterior view of a cisternogram two hours after lumbar injection (100 $\mu C i^{131}$ I HSA). Rapid movement over the cerebral convexities is present. No ventricular entry is detected. (b) Anterior view at 24 hours demonstrates normal concentration of radioactivity in the parasagittal region. 
pression and CSF diversionary shunting (Jacobson and Shapiro, 1964).

Skull radiographs, cerebral angiograms, and pneumoencephalograms have been employed in the diagnostic examination of these patients and the findings described. Radiological evaluation of these patients is important as it allows exclusion of more serious causes of similar symptomatology (posterior fossa neoplasms, hydrocephalus). Recently cisternography has been used to evaluate patterns of CSF movement and absorption in patients with pseudotumor cerebri (Schlesinger et al., 1965; Bercaw and Greer, 1970). The 'characteristic' image patterns described were at variance with those noted in our patients, thus stimulating this report.

\section{METHODS}

The cisternograms, clinical summaries, and other pertinent data on 10 patients with benign intracranial hypertension from four institutions were reviewed. Special emphasis was placed upon correlation at the time of study with the status of the patients' symptoms and whether or not treatment had been instituted. If cerebral angiograms and pneumoencephalograms had been obtained, these were compared with the isotope cisternograms (CSF images).

Since two of the radiopharmaceuticals employed, ${ }^{169} \mathrm{Yb}$ and ${ }^{111} \mathrm{In}$ in diethylenetriaminepentaacetic acid (DTPA) differ in molecular size from ${ }^{131}$ I human serum albumin (HSA) (600 vs. 67,000 M.W.), we correlated the CSF images with the radiopharmaceutical employed in the individual patient to deter-
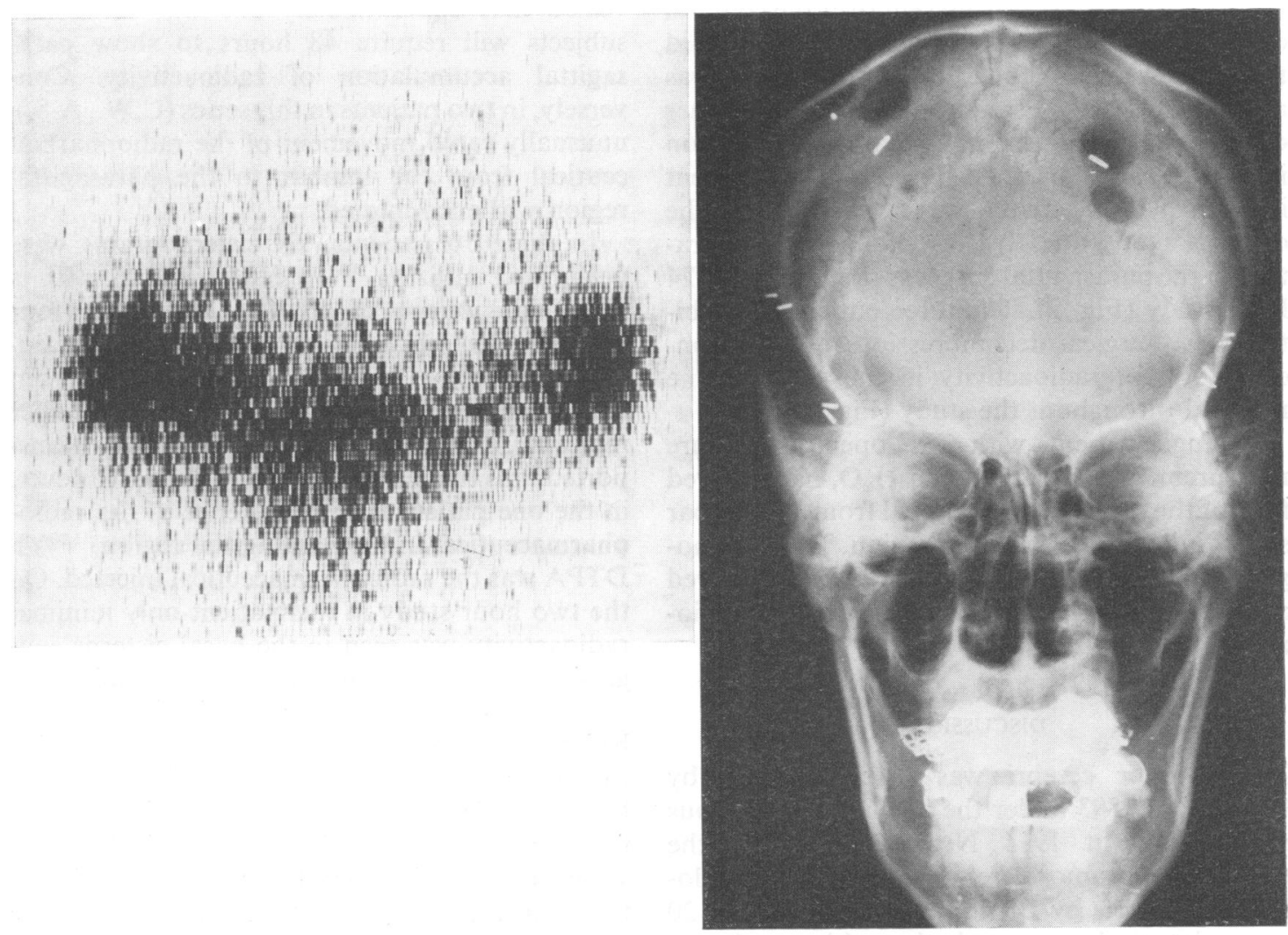

(a)

(b)

FIG. 3. (a) Anterior view cisternogram six hours after lumbar intrathecal injection of $450 \mu C i^{111}$ In DTPA. Abnormal collections of radioactivity are present in the area of the surgical subtemporal decompression. (b) The posteroanterior skull radiograph shows surgical defects, metallic clips, and burr holes. 
mine if there were differences that could be explained by this property alone.

Particular attention was directed to the temporal sequence of radioactivity movement from the basal cisterns to the parasagittal area and the presence or absence of ventricular entry. Since increased concentration of radiopharmaceutical in the area of the arachnoid villi in the parasagittal region has been reported, we specifically noted the presence or absence of this particular sign.

\section{RESULTS}

In this series of 10 patients, none showed ventricular entry of the radiopharmaceutical (Table). Seven patients had their cisternograms performed with labelled human serum albumin and in three chelates were used. Nine of 10 patients had basal radioactivity on the two hour study. By six hours, radioactivity was present over the cerebral convexities in five patients but had only reached the Sylvian area in four. By 24 hours there was activity over the cerebral hemispheres, either diffuse or concentrated in the parasagittal region in nine of the 10 patients (Fig. 1). In one patient increased radioactivity was present over the cerebral convexities by two hours. Concentration in the parasagittal area was present on the 24 hour study (Fig. 2). The three patients with bitemporal surgical decompression revealed concentration of radioactivity in the site of bone removal throughout the study (Fig. 3).

A single patient, with CSF opening pressure measurement of $500-600 \mathrm{~mm} \mathrm{H}_{2} \mathrm{O}$, had delayed flow of the radiopharmaceutical from the lumbar site of injection to the basal region. The cisternogram performed with ${ }^{169} \mathrm{Yb}$ DTPA showed abnormal parasagittal concentration of radioactivity after 24 hours.

\section{DISCUSSION}

Pseudotumor cerebri was first described by Quincke in 1893 under the apellation of 'serous meningitis'. In 1914 Nonne introduced the term 'pseudotumor cerebri'. Pneumoencephalographic reports by Davidoff and Dyke, some 20 years later, documented that this syndrome occurs in the presence of an anatomically normal ventricular system, although a certain percentage of these patients will have 'small' ventricles (Jacobson and Shapiro, 1964).
Bercaw and Greer (1970) and Schlesinger et al ${ }_{\mathbb{D}}^{Z}$ (1965) have described a CSF image pattern of delayed movement of ${ }^{131} \mathrm{I}$ human serum albumine with persistent concentration of radiopharma ceutical in the parasagittal area on delayed views (24 hours). No ventricular entry of radion pharmaceutical (characteristic of communica ting hydrocephalus) was present in their patients

In this series of 10 patients, delayed flow of radiopharmaceutical was encountered in only? four $(40 \%)$ and prolonged parasagittal concen tration occurred in only one $(10 \%)$. From a com $\frac{\sigma}{\overline{\frac{5}{}}}$ bined experience of the four authors of approxi mately 1,000 cisternograms, delayed flow and prolonged parasagittal activity occur in approxi mately $20 \%$ of normal subjects. Systematic re? view of 436 cisternograms (performed with ${ }^{131} \overrightarrow{\mathrm{L}}$ and ${ }^{99 m}$ Tc HSA or ${ }^{169} \mathrm{Yb}$ and ${ }^{111}$ In DTPA) re? vealed that approximately one-fifth of normaI subjects will require 48 hours to show pasa

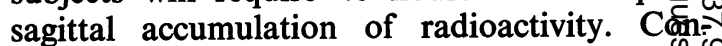
versely, in two patients in this series (C.W., A.S.) unusually rapid movement of the radiopharma ceutical from the lumbar to the parasagit⿱艹⿰氵⿹丁口欠 region was encountered.

In these 10 patients, six cisternograms wegres performed utilizing ${ }^{131}$ In HSA (RISA) with molecular weight of 67,000 . The other fôs patients had cisternograms employing rad active chelates (molecular weight 600). From comparative studies, it appears that the smallef molecule of the chelate is more rapidly trans ${ }^{ \pm}$ ported into the blood than is albumin. However in the one patient with persistence of the radios pharmaceutical in the parasagittal region, ${ }^{169} \mathrm{Y} / \mathrm{8}$ DTPA was the radiopharmaceutical injected. OP the two hour study in this patient only minima? radioactivity was seen in the basal cisterns sugo gesting slow ascension in the spinal canal.

Four patients had not received treatment before the cisternogram, three had conservative therapy consisting of diuretics and diet, and three had surgical subtemporal decompression. Except for persistence of radiopharmaceutical at the surgical sites bitemporally, treatment of an 8 type did not appear to alter the cisternographe pattern.

Correlation of cisternograms and pneumo encephalograms as well as animal data suggesi that images alone are not as sensitive as a conf bination of CSF images and measurements

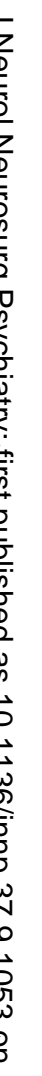


transfer of labelled molecules from the CSF space into the blood. Abbott and Alksne (1968) measured the transport of intrathecal ${ }^{125}$ I RISA to circulating plasma in 10 normal and four dogs with hydrocephalus which was produced by the kaolin technique. In the normal dogs the mean percentage of injected radioactivity found in the circulatory plasma at 24 hours was $46 \%$, whereas in the hydrocephalic animals only $16 \%$ was present. These findings correspond to those published by Van Wart et al. (1960) and in animals with communicating hydrocephalus by Strecker et al. (1973). In seven normal patients and six patients with communicating hydrocephalus the values were 48 and $24 \%$. It was concluded the 'RISA transport test' provided a sensitive means of detecting patients with communicating hydrocephalus. Bercaw and Greer (1970) employed the same test in three patients with benign intracranial hypertension and found that 'a decreased rate of plasma uptake' was present in two. In one patient the transfer test and cisternogram were repeated when the patient was asymptomatic and both studies were normal.

Three patients in this series had quantification of the disappearance of radiopharmaceutical from the CSF spaces utilizing a method previously described by Curl et al. (1972). A corrected count of intracranial activity for each imaging period up to 48 hours is obtained and normalized to represent percent of peak activity. In non-hydrocephalic patients, peak intracranial activity is maximal at six to 12 hours, falls to 40 $80 \%$ of peak by 24 , and $25-40 \%$ by 48 hours. The three patients with pseudotumor cerebri demonstrated completely normal radionuclide clearances (Abbott and Alksne, 1968) and were very different from the patient with communicating hydrocephalus in which the peak activity is not reached until 24 to 30 hours after injection and clearance is delayed. One patient had the CSF blood transfer determined by the method described by Bercaw and Greer (1970). There was delayed transfer. In a single patient in our series, transfer of the radiopharmaceutical (chelate) from the subarachnoid space into the urine was measured to be $1 \frac{1}{2}$ times normal.

The basic pathophysiological abnormality present in pseudotumor cerebri is unknown. Only limited pathological specimens have been obtained. Sahs and Joynt (1956) examined cortical biopsies in 10 patients with pseudotumor cerebri and found both intracellular and extracellular cerebral oedema in all. Yet in three patients with this syndrome who had postmortem examinations, no evidence of cerebral oedema was found (Foley, 1955). Albumin transfer studies of Schlesinger and Greer would tend to support the concept that a primary mechanism in the development of benign intracranial hypertension is an abnormality in CSF absorption.

Hakim (1973) has stressed the relation between intracranial venous pressure and the CSF pressure. Elevation of the venous pressure could result in both increased CSF pressure and an absorption defect (James et al., 1973). Why these patients have transient, remittant symptoms, normal sized ventricles, and do not appear subsequently to develop communicating hydrocephalus is unexplained.

In conclusion, from this limited series, we would question the value of a 'transfer test' in the differential diagnosis of pseudotumor cerebri and expect the cisternographic image pattern to be in the normal range in these patients.

We wish to express appreciation to Dr Martin Donner, Dr Guy McKhann, Dr George Udvarhelyi, and Dr Melvin Greer for inspiration. Scans in Figs 1 and 3 were obtained in the Division of Nuclear Medicine headed by Dr Wagner and the skull radiograph from the Neuroradiology section. (Fred Jenner Hodges III, chief).

\section{REFERENCES}

Abbott, M., and Alksne, J. F. (1968). Transport of intrathecal $I^{125}$ RISA to circulating plasma. Neurology (Minneap.), 18, 870-874.

Bercaw, B. L., and Greer, M. (1970). Transport of intrathecal ${ }^{131}$ I RISA in benign intracranial hypertension. Neurology (Minneap.), 20, 787-790.

Curl, F. D., Harbert, J. C., and McCullough, D. C. (1972). Quantitative cisternography: an aid to diagnosis. Cisternography and Hydrocephalus, pp. 441-451. Edited by J. C. Harbert. Thomas: Springfield, Ill.

Foley, J. (1955). Benign forms of intracranial hypertension'toxic' and 'otitic' hydrocephalus. Brain, 78, 1-41.

Guidetti, B., Giuffrè, R., and Gambacorta, D. (1968). Follow-up study of 100 cases of pseudotumor cerebri. Acta Neurochirurgica, 18, 259-267.

Hagberg, B., and Sillanpää, M. (1970). Benign intracrania hypertension (pseudotumor cerebri). Acta Paediatrica Scandinavica, 59, 328-339.

Hakim, S. (1972). Biomechanics of hydrocephalus. In Cisternography and Hydrocephalus, pp. 25-55. Edited by J. C. Harbert. Thomas: Springfield, Ill. 
Jacobson, H. G., and Shapiro, J. H. (1964). Pseudotumor cerebri. Radiology, 82, 202-210.

James, A. E., Jr, Strecker, E.-P., Novak, G., and Burns, B. (1973). Correlation of serial cisternograms and cerebrospinal fluid pressure measurements in experimental communicating hydrocephalus. Neurology (Minneap.), 23, 1226-1233.

Sahs, A. L., and Joynt, R. J. (1956). Brain swelling of unknown cause. Neurology (Minneap.), 6, 791-803.

Schlesinger, E. B., Bailey, S., and Groover, R. (1965). Patterns of central nervous system pathology as depicted by isotope encephalography. Transactions of the American Neurological Association, 90, 292-294.

Strecker, E.-P., Scheffel, U., Kelley, J. E. T., and James, A. E., Jr (1973). Cerebral fluid absorption in communicating hydrocephalus. Evaluation of transfer of radioactive albumin from subarachnoid space to plasma. Neurology (Minneap.), 23, 854-864.

Van Wart, C. A., Dupont, J. R., and Kraintz., L. (1960) Transfer of radioiodinated human serum albumin (RISA) from cerebrospinal fluid to blood plasma. Proceedings of the Society of Experimental Biology, 103, 708-710. 